\title{
Motivações e expectativas na busca de tratamento para o uso abusivo e dependência de crack, álcool e outras drogas*
}

\section{Motivation and expectations in treatment search for abusive use and addiction of crack, alcohol and other drugs}

\author{
Rebeca Rodrigues Gomes ${ }^{1}$, Mara Cristina Ribeiro ${ }^{2}$, Ewerton Cardoso Matias ${ }^{3}$, \\ Mércia Zeviani Brêda ${ }^{4}$, Elisabete Ferreira Mângia ${ }^{5}$
}

http://dx.doi.org/10.11606/issn.2238-6149.v26i3p326-335

Gomes RR, Ribeiro MC, Matias EC, Brêda MZ, Mângia EF. Motivações e expectativas na busca de tratamento para o uso abusivo e dependência de crack, álcool e outras drogas. Rev Ter Ocup Univ São Paulo. 2015 set.-dez.;26(3):326-35.

RESUMO: Pesquisa realizada em um Centro de Atenção Psicossocial Álcool e Drogas que objetivou analisar sob que circunstâncias ocorre a procura ao serviço e as motivações e expectativas que envolvem este processo e impulsionam a adesão ao tratamento. Trata-se de investigação exploratória e descritiva de caráter qualitativo que desenvolveu estudo bibliográfico e documental e realizou 10 entrevistas com usuários do serviço submetidas à Análise de Conteúdo. Os resultados apontam que a família exerce forte influência na motivação, tanto na busca do serviço quanto na adesão ao tratamento, outras motivações são a saúde fragilizada, violência experienciada pelo usuário em seu cotidiano e o desejo de mudança. As expectativas estão relacionadas à vontade de abandonar o consumo de drogas e à (re)construção de vínculos com a família e o trabalho. Conclui-se que os serviços especializados devem ampliar suas estratégias de inserção da família e da comunidade na atenção objetivando o fortalecimento do processo de cuidado. Investimentos em suas habilidades, autonomia e protagonismo também devem ser desenvolvidos para responder às expectativas dos usuários de reconstrução de suas histórias de vida.

DESCRITORES: Serviços de saúde mental; Usuários de drogas; Transtornos relacionados ao uso de substâncias; Alcoolismo; Reabilitação.
Gomes RR, Ribeiro MC, Matias EC, Brêda MZ, Mângia EF. Motivation and expectations in treatment search for abusive use and addiction of crack, alcohol and other drugs. Rev Ter Ocup Univ São Paulo. 2015 Sept.-Dec.;26(3):326-35.

\begin{abstract}
This research was conducted in a Psychosocial Care Center for Alcohol and Drugs and intended to analyze under which circumstances users seek the service, as well as the motivations and expectations that are involved in this process, and foster compliance to the treatment. It is an exploratory, descriptive, and qualitative investigation that involved a bibliographical and documentary study and 10 interviews with users of the service, which were submitted to Content Analysis. The results point out that families have a strong influence on motivation, both in the search for the serviced and in the compliance with the treatment. Other motivations are fragile health, violence experienced in the daily lives of users, and a wish for change. The expectations are related to their desire to quit using drugs and to (re)build their ties with their families and work. Specialized services are concluded to be required to extend their strategies to insert families and the community in the care, aiming at strengthening the care process. Investments in their skills, autonomy, and protagonism should also be developed to meet the expectations of users to rebuild their life stories.
\end{abstract}

KEY-WORDS: Mental health services; Drug users; Substancerelated disorders; Alcoholism; Rehabilitation.

\footnotetext{
* Pesquisa integrante do Grupo de Pesquisa em Saúde Mental e Saúde Coletiva do CNPq. Os dados são parte do Trabalho de Conclusão de Curso em Terapia Ocupacional da primeira autora.

1. Terapeuta Ocupacional. Graduada pela Universidade Estadual de Ciências da Saúde de Alagoas - UNCISAL, AL, Residente Multiprofissional em Saúde Coletiva com ênfase em gestão de Redes em Saúde, pela Universidade de Pernambuco - UPE, Arcoverde, PE, Brasil. E-mail: rebecaa_gomes@hotmail.com.

2. Terapeuta Ocupacional. Professora Adjunta do Curso de Terapia Ocupacional da Universidade Estadual de Ciências da Saúde de Alagoas - UNCISAL, Maceió, AL, Brasil. E-mail: marauncisal@yahoo.com.br

3. Terapeuta Ocupacional, Professor Auxiliar do Curso de Terapia Ocupacional da Universidade Estadual de Ciências da Saúde de Alagoas - UNCISAL. E-mail: ewerton to@hotmail.com

4. Enfermeira. Professora Adjunta do Curso de Enfermagem da Escola de Enfermagem e Farmácia da Universidade Federal de Alagoas UFAL. E-mail: merciazb@gmail.com

5. Terapeuta Ocupacional. Professora Associada do Curso de Terapia Ocupacional da Faculdade de Medicina da Universidade de São Paulo.E-mail: mangeli@usp.br

Endereço para correspondência: Mara Cristina Ribeiro. Universidade Estadual de Ciências da Saúde de Alagoas. Rua Jorge de Lima, 113. Trapiche da Barra,. Maceió, AL, Brasil. CEP: 57010-379. E-mail: marauncisal@yahoo.com.br
} 


\section{INTRODUÇÃO}

$\mathrm{O}$ uso de substâncias psicoativas está presente em diferentes culturas com características singulares ao longo da história. Na atualidade, essa questão ganhou características específicas e vem sendo compreendida como um problema multifatorial que requer ações de diversos setores, tais como a Saúde, Assistência Social, Educação, Justiça, entre outros. Há preocupação com o uso abusivo de álcool e drogas e os problemas decorrentes desse uso; tal situação pode ser discutida à luz das transformações econômicas, sociais e culturais caracterizadas pela fragilização dos laços sociais e de trabalho, em especial nos grandes centros urbanos ${ }^{1}$.

Para a atenção às pessoas em sofrimento e/ou com demandas decorrentes dos transtornos mentais e/ou do consumo de álcool, crack e outras drogas, o Sistema Único de Saúde propõe a organização da Rede de Atenção Psicossocial (RAPS) integrada, articulada e efetiva, composta por diversos pontos de atenção. Esta rede considera as especificidades loco-regionais e prioriza os serviços com base comunitária orientados pela lógica do cuidado centrado nas necessidades das pessoas. Assim, define como principais componentes da assistência: a Atenção Básica em Saúde, a Atenção Psicossocial Estratégica, a Atenção de Urgência e Emergência, Atenção Residencial de Caráter Transitório, a Atenção Hospitalar, as Estratégias de Desinstitucionalização e a Reabilitação Psicossocial².

No campo da Atenção Psicossocial Estratégica, encontram-se os Centros de Atenção Psicossocial (CAPS), serviços que, em conjunto com as ações de atenção básica, são responsáveis pela ordenação do cuidado em rede.

Os CAPS, em suas diferentes modalidades, são constituídos por equipes interprofissionais que devem desenvolver ações setoriais e intersetorias para atender as pessoas com transtornos mentais graves e persistentes e as pessoas com necessidades decorrentes do uso de crack, álcool e outras drogas. Desenvolvem trabalhos prioritariamente em espaços coletivos e de forma articulada com a rede de atenção à saúde bem como com as demais redes $^{2}$.

$\mathrm{Na}$ área específica da atenção e cuidado às pessoas com transtornos decorrentes do uso e dependência de substâncias psicoativas foram criados os Centros de Atenção Psicossocial álcool e drogas (CAPSad) que se constituem como serviços de atenção psicossocial ${ }^{3}$ que devem ofertar atendimentos capazes de responder às particularidades de cada sujeito, dos familiares e da comunidade em seu entorno, trabalhando na lógica de Redução de Danos (RD) e sendo apoiados por outras práticas de atenção comunitária ${ }^{1}$.

Nesta perspectiva, tem-se intensificado a implantação dos CAPSad III, destinados a proporcionar a atenção integral e contínua às pessoas com necessidades relacionadas ao consumo de álcool, crack e outras drogas. Estes têm como importante característica o funcionamento nas 24 horas do dia e em todos os dias da semana, inclusive finais de semana e feriados. Destinam-se a trabalhar de portas abertas, com plantões diurnos e noturnos de acolhimento ${ }^{4}$.

Garantem o acesso ao cuidado e responsabilização efetiva dos casos, por meio das ações desenvolvidas pela equipe interprofissional que deve realizar: atendimento individual para consultas em geral, atendimento psicoterápico e de orientação; oferta e manejo de medicação; atendimento em grupos para psicoterapia, grupo operativo e atividades de suporte social; oficinas terapêuticas; visitas e atendimentos domiciliares; atendimento à família, individual e em grupo; atividades de reabilitação psicossocial com vistas a estimular o protagonismo dos usuários do serviço e seus familiares; dentre outras ações ${ }^{4}$.

A busca e a adesão a serviços de atenção e cuidado a pessoas com necessidades relacionadas ao consumo de álcool, crack e outras drogas têm, cada vez mais, se mostrado um grande desafio, pois isso envolve fatores objetivos e subjetivos. Tal processo inclui questões inerentes ao sujeito, sua percepção sobre a questão do uso e suas relações com a equipe que o assiste, seu grau de envolvimento e participação na elaboração e decisão do projeto terapêutico, bem como a garantia da oferta e qualificação da assistência prestada e o apoio recebido dentro e fora do CAPS.

Neste contexto, o estudo objetivou analisar sob quais circunstâncias ocorre a procura ao serviço CAPSad e quais as motivações e expectativas envolvidas neste processo são capazes de contribuir para a adesão do tratamento ofertado.

Adotamos, nesta pesquisa, o termo "adesão" referido à decisão daqueles que procuram um tratamento de saúde, em segui-lo, compreendendo uma relação entre usuários, profissionais e serviço e o termo "motivação" enquanto algo que, na perspectiva do sujeito, influencia a direção para fazer, atuar, podendo ter origem externa (pressões, ações coercitivas) ou interna (aquilo que vem do próprio indivíduo $)^{5}$.

A pesquisa foi submetida à apreciação do Comitê de Ética em Pesquisa da Universidade Estadual de Ciências da Saúde de Alagoas e aprovada em 4 de setembro de 2013 sob o $\mathrm{n}^{\circ}$ CAAE 16225613.0.0000.5011. 


\section{METODOLOGIA}

A investigação, baseada na abordagem qualitativa, caracterizou-se como exploratória e descritiva. Para seu desenvolvimento foi realizada análise bibliográfica e documental, além de entrevista semiestruturada alinhada por questões norteadoras que tiveram como objetivo conhecer os entrevistados e possibilitar que estes pudessem descrever quais circunstâncias motivaram a busca ao tratamento e impulsionam a sua adesão.

As entrevistas foram realizadas no período de setembro a outubro de 2013 em um CAPSad III do município de Maceió, capital do estado de Alagoas.

Participaram 10 usuários (pessoas vinculadas ao serviço que recebem algum tipo de tratamento) que atenderam aos critérios de inclusão - ter iniciado o tratamento no serviço há menos de um mês, estar em condições de entender os propósitos da pesquisa no momento da entrevista e aceitar participar do estudo. A opção por investigar usuários com o período de início do tratamento igual ou menor que um mês justifica-se pelo fato de compreendermos que as circunstâncias que levaram à busca do tratamento ainda estão presentes de forma vívida, assim como as expectativas e motivações para a adesão deste devem estar sendo formadas nesse momento.

O número de participantes foi determinado pelo critério de saturação ${ }^{6}$ - foi previsto no desenho da pesquisa um número de participantes porém a decisão por incluir ou não novos entrevistados se deu a posteriori, considerando que o objetivo geral do estudo era restrito e havia significativa homogeneidade na população estudada, ou seja, por terem, os entrevistados, ido buscar e estarem frequentando um mesmo serviço de cuidado específico e por um período semelhante de tempo, constatou-se que os achados passaram a se repetir, o que justificou a interrupção da pesquisa para novas entrevistas.

Após a apresentação da pesquisa e seus objetivos, os sujeitos tiveram acesso ao Termo de Consentimento Livre e Esclarecido, sendo sanadas as dúvidas de cada ponto/ item a ele relacionados. Em seguida, as entrevistas foram realizadas em ambiente reservado, de forma individual, resguardando o sigilo e a privacidade do sujeito pesquisado e, com autorização prévia, todas foram gravadas - o que permitiu registrar de forma fidedigna as falas. O material gravado foi transcrito e revisado sistematicamente para a composição da análise.

Os resultados obtidos foram analisados por meio da técnica de Análise de Conteúdo, na modalidade análise temática, que consiste em descobrir os núcleos de sentido compostos na comunicação, considerando presença e fre- quências temáticas significativas para o objeto analisado ${ }^{7}$. Como procedimento metodológico para a análise, seguiram-se os três passos recomendados (pré-análise, exploração do material e tratamento dos resultados - inferência e interpretação) visando perscrutar e organizar o conteúdo das informações obtidas ${ }^{8}$.

Desta forma, foram identificadas as ideias centrais, realizando-se a interpretação dos sentidos de tais ideias e, a partir daí, o agrupamento delas em categorias empíricas classificadas por temas mais abrangentes em torno dos quais se desenvolveram as análises e aprofundamento dos temas.

\section{CENÁRIO DO ESTUDO}

O CAPSad em que o estudo foi desenvolvido iniciou suas atividades no ano de 2006, realizando atendimento, inicialmente, ao público infantojuvenil e classificado como CAPSII. Ao longo dos primeiros anos de seu funcionamento o serviço mudou seu perfil de atendimento - começou a atender apenas jovens adultos e depois estendeu $\mathrm{o}$ atendimento ao público em geral.

No ano de 2013, o serviço passou a funcionar na modalidade de CAPSad III, tendo assim sua proposta de atendimento ampliada e constituindo-se, até o momento, como o único serviço municipal nessa modalidade. Tem média de busca de tratamento de 80 usuários por mês, atendendo a aproximadamente 70 usuários por turno. Oferece grupos terapêuticos, atendimentos individuais, distribuição de medicamentos e atendimentos aos familiares.

Ainda de acordo com dados do serviço, a maior parte dos usuários atendidos refere que as principais drogas que utilizam são, nessa ordem, álcool, crack e maconha - o tabaco não foi considerado.

As informações deste estudo foram obtidas na Coordenação Administrativa do serviço no período da coleta dos dados da pesquisa.

\section{RESULTADOS}

Dos dez usuários entrevistados, todos são do sexo masculino, as idades variaram entre 18 aos 47 anos, metade referenciou viver em situação de rua. O desemprego aparece como situação atual para a grande maioria bem como o histórico de internação em comunidades terapêuticas.

A Tabela 1 apresenta as informações sobre idade, estado civil, se possuem filhos ou não e a escolaridade.

A Tabela 2 apresenta as informações sobre a situação atual de moradia e trabalho, se já estiveram internados em hospitais psiquiátricos ou em comunidades terapêuticas e o tempo que estão em tratamento no CAPS em que o estudo foi realizado. 
Tabela 1 - Informações sobre os usuários

\begin{tabular}{|c|c|c|c|c|c|}
\hline Entrevista & Sexo & Idade & Escolaridade & Estado Civil & Com filhos \\
\hline 1 & M & 21 & $9^{\circ}$ ano & Casado & Sim \\
\hline 2 & M & 29 & $5^{\circ}$ ano & Solteiro & Sim \\
\hline 3 & M & 28 & $4^{\circ}$ ano & Solteiro & Sim \\
\hline 4 & M & 47 & Ensino Médio Incompleto & Solteiro & Sim \\
\hline 5 & M & 27 & $5^{\circ}$ ano & Separado & Sim \\
\hline 6 & M & 29 & $8^{\circ}$ ano & Solteiro & Não \\
\hline 7 & M & 27 & $6^{\circ}$ ano & Solteiro & Não \\
\hline 8 & M & 36 & Fundamental Incompleto & Solteiro & Sim \\
\hline 9 & M & 22 & $9^{\circ}$ ano & Solteiro & Não \\
\hline 10 & M & 18 & $5^{\circ}$ ano & Separado & Não \\
\hline
\end{tabular}

Tabela 2 - Situação atual de moradia e trabalho dos usuários

\begin{tabular}{|c|c|c|c|c|c|}
\hline Entrevista & Situação Atual de Moradia & Situação Atual de Trabalho & $\begin{array}{c}\text { Internação } \\
\text { em HP }\end{array}$ & $\begin{array}{c}\text { Internação } \\
\text { em CT }\end{array}$ & $\begin{array}{c}\text { Tempo no } \\
\text { CAPS (dias) }\end{array}$ \\
\hline 1 & Em casa, com a família & Desempregado & Não & Sim & 30 \\
\hline 2 & Situação de rua & Desempregado & Não & Sim & 28 \\
\hline 3 & Situação de rua & Marceneiro, desempregado & Não & Sim & 28 \\
\hline 4 & Situação de rua & Desempregado & Não & Sim & 3 \\
\hline 5 & Situação de rua & Desempregado & Sim & Sim & 5 \\
\hline 6 & Em casa, com a avó & Desempregado & Não & Sim & 24 \\
\hline 7 & Em casa, com a mãe & Desempregado & Não & Sim & 8 \\
\hline 8 & Em casa, com a mãe & Funcionário Público & Sim & Não & 30 \\
\hline 9 & Em casa, com a irmã & Padeiro, desempregado & Não & Sim & 30 \\
\hline 10 & Situação de rua & Desempregado & Não & Sim & 25 \\
\hline
\end{tabular}

Os dados produzidos por meio das entrevistas foram organizados para a análise em categorias temáticas, definidas a priori, para o alcance dos objetivos da investigação. Foram elas:

1) Motivações para a busca do serviço;

2) Motivações para a permanência no serviço;

3) Expectativas em relação ao tratamento.

\section{Motivações para a busca do serviço}

As entrevistas revelaram que a família tem forte influência na tomada de decisão pela busca do tratamento: o isolamento do usuário, associado ao conflito gerado por outras mudanças comportamentais diante dos familiares e o desejo de recuperar ou fortalecer os lações familiares podem ser apontados como grandes motivadores.

[...] porque eu queria estar na minha casa, e minha mãe não queria eu dentro de casa daquele jeito, [...] ter tudo isso que eu estou tendo de volta foi o que contribuiu pra eu querer vir me tratar no CAPS. (U1)

Porque eu não aguentava mais sofrer. Chorando, sem amigo [...], devido não poder ver minhas filhas, [...] agora estou na rua, ficou mais dificil o acesso [...].quis vir também porque já tinha perdido meu casamento, tinha me isolado das amizades, me afastei do meu emprego. E aí minha mãe, minha vó me incentivaram a vir para cá. (U2).

O envolvimento com o tráfico, as vivências de violência, o risco de morte e as ocorrências policiais também serviram para a tomada de posição pela busca por proteção e desejo de mudanças.

[...] eu tinha um irmão que era usuário, mataram ele na minha frente [...]. eu fiquei com medo também de 
morrer. Eu quis sair dessa vida. [...] eu já cheguei ao fundo do poço. E tentaram me matar três vezes e não conseguiram. (U1)

Usar droga, ter bronca com os "vagabundos", com os traficantes, roubar a droga deles. E agora tem muitos querendo me pegar. Assim não dava mais. (U3)

[...] Na verdade o pessoal do tráfico não faz medo, não... Nenhum. É mais a polícia mesmo. (U5)

A busca por cuidados médicos e a necessidade de encaminhamentos para outros serviços de saúde também foram apontados como fatores relevantes para a motivação da busca do tratamento no CAPSad.

Eu tenho problema de saúde e é também por isso que eu estou aqui [...] não é só por causa do álcool e do meu filho. Eu já estou com três médicos marcados. (U4)

Eu vim porque estava usando muita droga. Cheguei a ponto de desmaiar, de tanto usar droga, sem comer, sem me cuidar... Foi quando vi que precisava de ajuda... Ai eu vim só, procurei, procurei e achei. (U5)

Ao se referirem às consequências negativas e dinâmica compulsiva de uso, os participantes, apesar de não perceberem ou identificarem a RD no seu cotidiano, desenvolvem estratégias para reduzir os riscos e danos baseados na própria vivência e experiência do uso.

Começava a fumar de dia, passava a noite toda, quando acordava no outro dia, parecia que tinha levado uma surra. [...] eu fumo um baseado, porque bate muita vontade de fumar crack e para não usar, eu fico só na maconha, porque se der a primeira paulada numa pedra, você não para mais, é o dia todo correndo atrás, arriscado a roubar, fazer o que você não quer, nem pode, só pra fumar (U2).

A percepção e conscientização sobre seu estado de saúde e questões de cunho social, e a possível relação desses fatores com o uso de substâncias psicoativas, podem servir para impulsionar a busca do usuário pelo serviço.

Eu vim por conta própria, porque me sinto fraco, porque a dependência química não é fácil.. (U3)

Ninguém me obrigou. Minha mãe me ajudou, veio comigo... Eu tenho minhas filhas, minha mãe já é idosa, e eu preciso de uma vida social... Também tive muito prejuízo financeiro. (U8)

\section{Motivação para a permanência no serviço}

Vários fatores foram relatados pelos entrevistados como motivadores da continuidade do tratamento. A referência mais importante foi atribuída à família. Destacou-se o incentivo e retorno da confiança da figura materna e o desejo de reaproximação de outros familiares, com enfoque principal nos filhos.

Só o que me motiva a continuar é minha mãe. O apoio que ela me deu, mesmo com tudo que eu já fiz para ela, ela nunca me deixou por aí me acabando na droga, e porque eu quero agora reconquistar a confiança dela. (U6)

O motivo são minhas filhas. Na verdade, elas são o motivo de eu estar vivo hoje, de estar vivo agora, porque se não fosse elas, eu nem estava nessa situação. É bem provável que eu já estivesse morto. (U5)

Outro fator relevante para a motivação dos sujeitos a continuarem no tratamento, foi a diversificação das ofertas de atenção oferecida no CAPSad.

[...] Estou tirando meus documentos, estão me ajudando, já tirei minha identidade, me levaram na Defensoria Pública, pegaram a papelada, tiraram identidade... (U9)

Eu gosto muito de conversar. Você já deve ter percebido... E, eu só estou aqui há poucos dias, mas tem uns profissionais aqui muito bons, e eu converso, tem me feito muito bem. (U4)

Eu participo sempre dos grupos, inclusive eu estou bem focado no teatro, estou adorando. Isso tem me incentivado bastante aqui, tenho aprendido muito a melhorar minha expressão, minha forma de falar, e é uma coisa que para alguns é besteira, mas para mim, é fundamental. (U5)

As entrevistas demonstraram, também, a determinação dos sujeitos frente aos desafios ainda enfrentados, sendo, então, um reforço para a motivação.

As dificuldades que estou passando, tenho que colocar na cabeça que é só mais um obstáculo e que eu tenho que passar por cima... (U2)

Eu já sofri demais, e não aguento mais, e ainda estou sofrendo, mas agora estou me erguendo cada vez mais, através de todos aqui que estão me ajudando. (U3) 
Também foram citados pelos participantes outros fatores relevantes capazes de influenciarem na continuidade do tratamento, são eles: a disponibilidade para o enfrentamento dos obstáculos e a valorização dos pequenos ganhos.

\section{Expectativas em relação ao tratamento}

Os entrevistados indicaram seu envolvimento em novos projetos de vida, planos que consideraram concretos como: abandono definitivo da droga ou desejo de se manterem no tratamento e continuarem usando a droga de maneira mais responsável; o retorno aos estudos, ao trabalho e; planos de se tornarem aptos a controlarem as finanças.

Apontaram alguns desejos como o de sair das ruas ou dos albergues e de ser capaz de sustentar a própria casa, (re)construir seus vínculos familiares e engajar-se na reabilitação de outros sujeitos.

Observou-se nos relatos que as expectativas relacionadas ao tratamento, o desejo de mudanças e viabilização de projetos palpáveis estão condicionados a novas atitudes e abandono do uso da droga.

Eu espero muita coisa, sabe? Que tenho que acreditar que vou conseguir, que vou ficar bom, saudável. Eu quero ter minha família, mas antes disso, quero mudar de atitude nas minhas ações. Porque eu já fiz muita coisa errada, já roubei muito por causa de droga, já fiz minha mãe sofrer demais [...] Agora eu quero mudar pra valer. Pra poder conquistar o que eu quero, me amar mais, ter força de vontade para poder parar. (U6)

A intenção dos sujeitos de voltarem aos seus empregos ou o anseio de capacitarem-se para conseguirem novos empregos, além da expectativa de retomarem os estudos, destacam-se como caminhos para a independência e autonomia.

Eu trabalhava com marcenaria... Mas eu queria me capacitar em outra coisa. Se eu tivesse uma chance, eu queria muito voltar a estudar e concluir os estudos, que eu estudei só até a quarta série.(U3)

Um homem precisa de trabalho digno, e eu quero poder também voltar a trabalhar, que eu já trabalhei muito de servente, e tenho um emprego lá, quero ficar bom para voltar.(U6)

Os conteúdos referem-se à expectativa dos entrevistados de que a partir do momento em que estiverem inseridos no mercado de trabalho, terão como prioridade o plano de sair das ruas ou albergues, considerando, também, essa estratégia como um veículo para (re)construção de vínculos familiares e distanciamento da situação de vulnerabilidade nas ruas.

Eu quero arrumar dinheiro para comprar minha casa, sair da rua... para ter minhas filhas, uma familia. (U2)

Eu preciso parar de beber, para trabalhar, ter um canto, para sair do albergue e ajudar meu filho... Eu penso em ter minha casa, não para mim, mesmo, mas para ele, futuramente. (U4)

Quero arrumar dinheiro para ter um quartinho para onde ir dormir, para não ficar na rua... Porque na rua é perigoso. (U5)

Os entrevistados expressaram grandes expectativas relacionadas à (re)construção dos vínculos familiares.

Eu espero que mude tudo. Porque o ser humano sem familia não é nada. [...] E a verdade é essa: a intenção de juntar minhas filhas. E a verdade é porque estou $f$ cando velho. Não sou mais menino, não, um garoto, não. Quero cuidar das minhas filhas como um homem. (U2)

É uma coisa que eu pretendo muito, construir uma família, ter minha esposa, meus filhos. Porque eu até tive um filho, mas a mulher não quis, a avó não quis que eu registrasse. (U3)

Outro desejo apresentado pelos entrevistados foi o de, após reabilitados, envolverem-se na reabilitação de outros sujeitos.

Sempre, quando estou na rua, e vejo usuário de droga, eu chego lá, converso, falo do CAPSad, faço convite para ele também vir se recuperar [...] A minha vida está uma maravilha aqui, e eu pretendo ficar até o fim, e cada vez trazendo mais irmão pra se recuperar aqui comigo.(U1)

Sei que a melhor ajuda a um dependente químico, não importa que a pessoa seja estudada, a melhor ajuda é um dependente recuperado. Ele pode, porque ele passou por tudo. Porque nós passamos tudo a mesma coisa, só perda, só destruição. [...] eu vou ajudar o próximo, colegas meus que estão nessa vida... Tem vários, mesmo. (U3)

Observou-se que os participantes acreditam na possibilidade do tratamento promover mudanças significativas em suas vidas, mas, todas elas foram associadas ao primeiro plano: o abandono do uso abusivo de 
substâncias, levando em consideração o desejo do abandono total da droga. É preciso destacar, porém, que aqueles que já vivenciaram a experiência de tratamentos voltados para a abstinência total, consideraram esta abordagem ineficaz e acreditam em uma reabilitação que possa se desenvolver de maneira gradativa.

\section{DISCUSSÃO}

Evidenciou-se que vínculos familiares foram rompidos ou prejudicados em decorrência do uso do álcool e/ ou de outras drogas. No entanto, os entrevistados mostram que, mesmo desgastadas em consequência dos riscos e problemas relacionados ao uso e às recorrentes recaídas, suas famílias permaneceram como principal apoio e incentivo para a busca da reabilitação - sendo referidas, com frequência, as figuras da mãe e dos filhos. Desta forma, a procura pelo CAPSad aparece como instrumento para o resgate das relações, ao mesmo tempo em que se configura como uma resposta do sujeito às expectativas e estímulo dos familiares.

Souza et al. ${ }^{9}$ afirmam que, mesmo os vínculos que se mantém, são permeados por ambiguidades e estresse, em função do desgaste das relações e da perda da confiança resultado das recaídas. Portanto, os serviços comprometidos com o cuidado especifico dessa população devem direcionar as suas ações para estimular ofortalecimento e a melhora da qualidade desses vínculos familiares ${ }^{10}$, pois como pudemos observar muitas vezes são os únicos que se mantém.

Outro aspecto bastante importante para ser considerado é que a representação do uso de drogas na sociedade modifica-se com o tempo e contexto. Os significados são transitórios e o uso das substâncias suscitam discussões sobre a legalidade do uso. A intolerância e a criminalização têm colaborado para que estes sujeitos carreguem em seu cotidiano as marcas do impune, do fora da lei e do dependente químico que precisa ser curado.

As consequências deste cenário multifacetado, polarizado entre o cuidado e a violência, concretiza-se da seguinte forma: sujeitos afastados de seu convívio familiar, vítimas do desamparo, dormindo em albergues ou nas ruas e demonizados em consequência do uso de drogas.

Os participantes do estudo expressaram o medo de sofrer violência não apenas de traficantes e policiais, como o de serem punidos pela Lei, o que contribuiu para o desenvolvimento de uma consciência crítica e o reconhecimento sobre a necessidade de mudança, motivando-os pela busca do cuidado.

Importante pontuar que na prática profissional tem sido comum ouvir relatos, muitas vezes desesperados, de sujeitos ou de seus familiares sobre as ameaças de morte decorrentes de dívidas não pagas e envolvimento com o tráfico. Muitos fogem, mudam-se para a casa de parentes, outros procuram o serviço por sentirem necessidade de acolhimento e afastamento do meio ambiente em que vivem ${ }^{11,12}$.

As falas indicam que ao chegarem ao serviço muitos se sentiam fragilizados, com necessidades diversas, relatam que foram acolhidos, avaliados pelo psiquiatra, medicados e, alguns, permaneceram no acolhimento noturno. Quando preciso, foram encaminhados a outros serviços de atenção para a realização de exames de saúde, demonstrando, desta forma, estarem cientes de que esses serviços e encaminhamentos seriam, de fato, encontrados. Estes fatores são influenciadores na motivação para a busca do serviço.

Foi possível detectar, portanto, que no contexto dos depoimentos, os usuários evidenciam realizar estratégias para amenizar os danos sociais e à saúde. Partindo-se das premissas do cuidado humanizado e de que a busca por cuidado adequado, a partir das necessidades de cada usuário, também são fatores que determinam a motivação para estar no serviço, a RD se coloca enquanto uma estratégia que visa minimizar os agravos referentes às várias situações que envolvem o uso de substâncias psicoativas.

$\mathrm{Na}$ análise das entrevistas percebe-se que as motivações citadas para a busca do serviço surgem no cotidiano e contexto de vida, porém, é possível inferir que estas resultam na percepção da necessidade de mudança e construção de novos projetos de vida, gerando nos sujeitos a motivação interna e mobilização pessoal para a busca e adesão ao tratamento.

Outro fator relevante que é possível inferir é que a família não só exerce papel fundamental para a tomada de decisão pelo busca do serviço, como também é apontada como fator relevante que motiva a sua permanência nele.

Desta forma, o estudo evidencia a importância da participação da família no tratamento e fortalece a ideia de que as relações familiares, mesmo que desgastadas, devem estar no foco do cuidado, por significarem um dos primeiros passos no resgate das redes sociais perdidas.

As entrevistas permitem observar que o CAPSad é reconhecido como catalizador de diversas necessidades que transcendem o tratamento clínico. Souza et al. ${ }^{9}$ afirmam que, em contrapartida aos vínculos rompidos ou fragilizados dos sujeitos, o CAPSad se coloca como o principal serviço de saúde capaz de favorecer o fortalecimento e ampliação das redes sócio relacionais.

A oferta de espaços grupais com temáticas variadas promove o refinamento do vínculo entre usuários e o serviço, entre os próprios usuários e entre os profissionais e usuários, sendo também determinante para a decisão a permanência no serviço. 
Figlie et al. ${ }^{13}$ destacam a importância da inserção dos sujeitos nos grupos terapêuticos. Consideram que a ação terapêutica do grupo pode se processar pela possibilidade de cada um se ver e se refletir nos outros participantes, podendo assim, reconhecer aspectos que estão negando. O grupo possibilita o compartilhamento de experiências, o que facilitará a melhor percepção do funcionamento da pessoa por meio das interações ocorridas no contexto grupal.

Com relação à perspectiva de mudança e viabilização de novos projetos, evidenciadas nas falas, Rigotto e Gomes ${ }^{14}$, afirmam que muitas vezes é na ruptura, na percepção do fracasso, no confronto entre o que se quer e o que não se quer, que emerge a compreensão do possível, do planejamento viável. A determinação por mudança é, na verdade, a junção entre a consciência do problema e o desejo de mudança. Salientam que não é possível iniciar um projeto de mudança, sem que seja atendida essa condição.

Alves et al. ${ }^{15}$, ao descreverem as dificuldades encontradas no contexto de reabilitação e reinserção no mercado de trabalho, indicam que o tratamento precisa ser voltado não só para a cessação do consumo de substâncias, mas também para os déficits cognitivos e sociais do sujeito, comprometidos pelo uso abusivo de substâncias.

Além disso, é preciso considerar que o desemprego e as dificuldades enfrentadas são, também, consequências do estigma que carregam, dificultando a oportunidade de uma vaga de trabalho ou até mesmo a permanência num emprego.

Alguns fatores identificados tais como o uso compulsivo de drogas - reconhecido pelos usuários como o maior causador do enfraquecimento dos laços com os familiares e com o trabalho -, além da falta de capacitação para $\mathrm{o}$ trabalho e baixa escolaridade, nos remetem às proposições que Caste $^{16}{ }^{16}$ define sobre os processos de vulnerabilidade e desfiliação social. Na análise contextual dos participantes da pesquisa é possível afirmar que alguns se encontram na zona de vulnerabilidade, que se caracteriza pela ausência de trabalho, mas com a presença - mesmo que fragilizada - dos apoios relacionais ou, inversamente, a presença de trabalho e ausência ou fragilidade na rede sócio relacional. Tal situação dinâmica pode levar o sujeito para a zona de desfiliação, caso a ruptura dos vínculos com o mercado de trabalho e com as redes sócio relacionais se vejam concomitantemente perdidas.

A Figura 1 apresenta as zonas de variação da coesão social proposta por Castel ${ }^{16}$. Nessa perspectiva, as ações de reabilitação devem estar focadas na construção de vínculos para possibilitar a saída da zona de desfiliação, na qual, como pudemos verificar, alguns já se encontram, e fortalecimento dos vínculos já existentes para que a zona de vulnerabilidade seja uma passagem desse processo, pois se entende que essas zonas são dinâmicas, ou seja, suas fronteiras são móveis, operando-se passagens incessantes de uma à outra ${ }^{16}$.

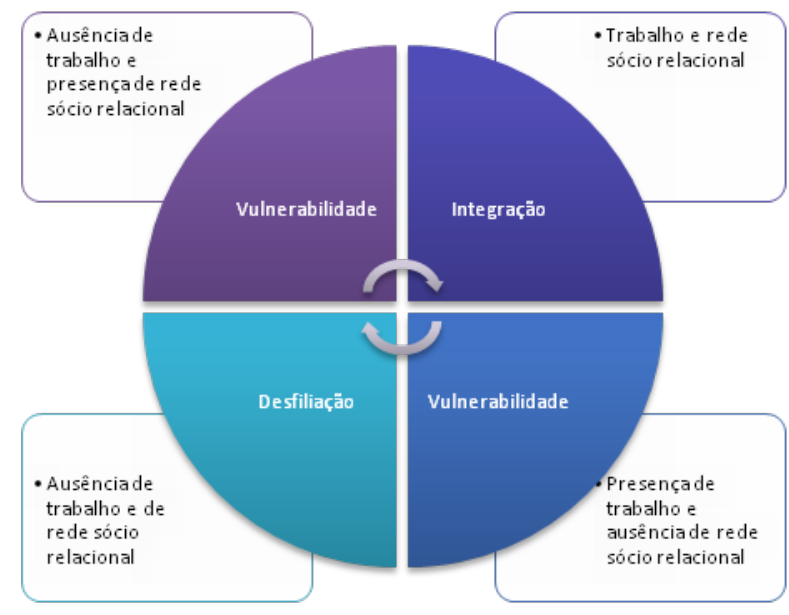

Figura 1 - Zonas de variação da coesão social $\left(\right.$ Castel $\left.^{16}\right)$

Por último, mas não menos importante, são os apontamentos dos entrevistados do estudo relacionados ao desejo de se envolveram na reabilitação de outros sujeitos que se encontram em situações muito parecidas com as quais eles estavam antes de chegarem aos serviços e aderirem ao tratamento.

Jorge e Brêda ${ }^{17}$, ao trazerem a experiência do Consultório de Rua abordam a possibilidade de ex-usuários e usuários de álcool e outras drogas trabalharem com a estratégia da $\mathrm{RD}$, por meio de sua inserção nas equipes, tornando-os, então, agentes redutores de danos, capazes de contribuir para o fortalecimento desta forma de cuidado. A atual equipe dos Consultórios na Rua ainda mantém esses profissionais e os consideram extremamente importantes no processo do cuidado.

Podemos afirmar, portanto, que o engajamento dos usuários dos CAPSad em ações relacionadas à busca do serviço por novos usuários, à promoção de saúde, ao cuidado na comunidade no entorno, entre outros, deve ser considerado.

\section{CONCLUSÃo}

Considerando que os discursos dos entrevistados apontam para a importância da participação da família, tanto no processo de busca e continuidade do tratamento, quanto em seus projetos de vida; e que as atividades propostas no CAPSad, principalmente os grupos terapêuticos, teatrais e 
esportivos têm exercido papel fundamental para o estímulo desses usuários a continuarem no processo de reabilitação, percebemos a necessidade de ampliação e articulação das estratégias de atuação deste serviço nesses campos, a fim de inserir as famílias no processo de atenção à saúde dos usuários, de maneira que estas também recebam o cuidado e percebam que são essenciais para que os sujeitos se mantenham motivados e comprometidos com o tratamento.

Deve-se considerar que a própria condição de vulnerabilidade percebida nos discursos dos entrevistados pode contribuir para as recaídas e interrupções no tratamento. Desta forma, tanto o envolvimento da família, quando possível, quanto a ampliação e o aprimoramento de atividades terapêuticas e de reinserção oferecidas poderão fortalecer este usuário em seu processo de reabilitação.

Diante da grande expectativa dos usuários de reconstituírem laços sociais interrompidos ou fragilizados e (re)construírem vínculos com o trabalho, é importante que as ações do CAPSad envolvam a comunidade, promovendo esclarecimentos, desmistificações e quebra de paradigmas. Além disso, faz-se mister a proposição de ações integradas e interdisciplinares, que proporcionem aos sujeitos sua reinserção social por meio de descobertas e aprimoramento de habilidades, capacidade de resolução de problemas, experimentação e exercício de cidadania, bem como resgate da autonomia, autoestima e de seus papéis dentro da família e da comunidade, respondendo, desta forma, às expectativas de reconstrução de suas histórias de vida.

AGRADECIMENTOS: À Jorgina Sales Jorge pela contribuição na revisão final do artigo.

\section{REFERENCIAS}

1. Brasil. Ministério da Saúde. Secretaria Executiva. Coordenação Nacional de DST/Aids. A Política do Ministério da Saúde para atenção integral a usuários de álcool e outras drogas. Brasília; 2003. Disponível em: http://bvsms.saude.gov.br/bvs/ publicacoes/pns_alcool_drogas.pdf

2. Brasil. Ministério da Saúde. Portaria 3088, de 23 de dezembro de 2011. Institui a Rede de Atenção Psicossocial para pessoas com sofrimento ou transtorno mental e com necessidades decorrentes do uso de crack, álcool e outras drogas, no âmbito do Sistema Único de Saúde. Brasília; 2011. Disponível em: http://bvsms.saude.gov.br/bvs/saudelegis/gm/2013/ prt3088_23_12_2011_rep.html.

3. Brasil. Ministério da Saúde. Portaria GM/MS n. ${ }^{\circ} 336$, de 19 de fevereiro de 2002. Disponível em: http://www.saude.mg.gov. br/images/documentos/Portaria_336.pdf.

4. Portaria $\mathrm{n}^{\mathrm{o}} 130$, de 26 de janeiro de 2012. Redefine o Centro de Atenção Psicossocial de Álcool e outras Drogas 24 h (CAPS AD III) e os respectivos incentivos financeiros. Brasília; 2012. Disponível em: http://bvsms.saude.gov.br/bvs/saudelegis/ gm/2012/prt0130_26_01_2012.html.

5. Ryan RM, Plant RW. Initial motivations for alcohol treatment: relations with patient characteristics, treatment involvement and dropout. Addict Behav. 1995;20(3):279-97._doi: 10.1016/0306-4603(94)00072-7.

6. Fontanella BJB, Ricas J, Turato. Amostragem por saturação em pesquisas qualitativas em saúde: contribuições teóricas. Cad Saúde Pública. 2008;24(1):17-7. doi: 10.1590/S0102$-311 X 2008000100003$

7. Minayo MCS. O desafio do conhecimento: pesquisa qualitativa em Saúde. 12a ed. São Paulo: Hucitec; 2010.

8. Bardin L. Análise de conteúdo. São Paulo: Edições 70; 2011.

9. Souza J, Kantorski LP, Mielke FB. Vínculos e redes sociais de indivíduos dependentes de substâncias psicoativas sob tratamento em CAPS AD. SMAD Rev Eletrônica Saúde Mental Álcool Drog (Ed. port.). 2006;2(1). Deisponível em: http://pepsic.bvsalud.org/scielo.php?pid=S1806$-69762006000100003 \&$ script $=$ sci_arttext.

10. Souza J, Kantorski LP, Vasters GP, Luis MAV. Rede social de usuários de álcool, sob tratamento, em um serviço de saúde mental. Rev Latino-Am Enferm. 2011;19(1):140-7. doi: http:// dx.doi.org/10.1590/S0104-11692011000100019.

11. Ferreira ACZ, Borba LO, Capistrano FC, Czarnobay J, Maftum MA. Fatores que interferem na adesão ao tratamento de dependência química: percepção de profissionais de saúde. Rev Min Enferm. 2015;19(2):150-6. doi: 10.5935/14152762.20150032.

12. Moraes M. O modelo de atenção integral à saúde para tratamento de problemas decorrentes do uso do álcool e outras drogas: percepções de usuários, acompanhantes e profissionais. 
Ciênc Saúde Coletiva. 2008;13(1):121-33. doi: 10.1590/ S1413-81232008000100017.

13. Figlie NB, Melo DG, Payá R. Dinâmicas de grupo aplicadas no tratamento da dependência química: manual teórico e prático. São Paulo: Roca; 2004.

14. Rigotto SD, Gomes WB. Contextos de abstinência e de recaída na recuperação da dependência química. Psicol Teor Pesq. 2002;18(1):95-106. doi: 10.1590/S0102-37722002000100011.

15. Alves HNP, Ribeiro M, Castro DS. Cocaína e crack. In: Diehl
A, Cordeiro DC, Laranjeira R. Dependência química: prevenção, tratamento e políticas públicas. - dados eletrônicos. Porto Alegre: Artmed; 2011. p.170-9.

16. Castel R. Da indigência à exclusão, a desfiliação: precariedade do trabalho e vulnerabilidade relacional. In: Lancetti A, organizador. Saúde loucura 4. São Paulo: Hucitec; 1994.

17. Jorge JS, Brêda MZ. Consultório de rua: novo espaço, novo dispositivo, inovadora forma de cuidado. In: Soares $\mathrm{MH}$, Bueno SMV, organizadores. Saúde mental: novas perspectivas. São Paulo:Yendis; 2011. p.7-86.

Artigo recebido em: 28.09.15

Artigo aceito em: 19.11.15 